\title{
Comparative Study on Effect of Breathing and Aerobic Exercise on General Health in Asymptomatic Population
}

\author{
Pranati Hota, (MPT), Dr. Patitapaban Mohanty, Ph. D., Assoc. Prof (PT), \\ Mrs. Monalisa Pattanaik, Asst. Prof. (PT) \\ Swami Vivekananda National Institute of Rehabilitation Training and Research, Olatpur, Bairoi, Cuttack, \\ Odisha, India
}

\begin{abstract}
:
Background: Breathing and aerobic exercises produce different types of physiological responses in healthy individuals. Aim of the study is to find the effect of breathing exercises against aerobic exercises in improving the general health of asymptomatic population.

Materials and Methods: The selected subjects were randomly assigned into two groups (Breathing and Aerobic) with 16 subjects each. Breathing group performed breathing exercise in supine, sitting,crook lying and standing with inspiration : expiration ratio 1:1,1:2,1:2:2 for a periods of 6 weeks. Aerobic group performed cycling, stair climbing, walking on ramp. Total duration of exercise was 5 days per week for 6 weeks.

Results: Results of the study showed significant reduction in pulse rate, blood pressure and skin fold thickness from pre to post intervention in both breathing and aerobic group. It also found that, there was significant improvement in vital capacity, $\mathrm{MVV}, \mathrm{VO}_{2}$ Max and quality of life from pre to post intervention in both breathing and aerobic group. However there was no statistically significant difference between both groups with regard to the above variables except VO2 Max, which was significantly improved more in aerobic group and skin fold thickness, which was significantly reduced in aerobic group.

Conclusion: The study demonstrate that breathing and aerobic exercises are effective in improving cardio respiratory parameters and quality of life in asymptomatic population however aerobic exercises has better effect in reduction of skin fold thickness and improvement in $\mathrm{VO}_{2} \mathrm{Max}$.

Key words: Breathing exercise, Aerobic exercise, Pulse rate, Systolic and Diastolic blood pressure, Vital capacity, $\mathrm{MVV}, \mathrm{VO}_{2}$ Max, 12-Minute walk test, Skin fold thickness, Health related quality of life
\end{abstract}

\section{Introduction}

Physical activities are considered to be the very important part of a human`s life. Physical activity keeps our mind fresh and our body active. For maintenance of a good life style and healthy status, we require adequate regular meals, proper sleep, physical activities, which should be of appropriate intensity, frequency and duration. With advancement of time people have modified their life style with very less physical activities and more mental stress [1].

The meaning of the word "aerobics" is to obtain free oxygen. Aerobic exercise is a type of physical exercise which can vary from low intensity to high intensity and mediated through aerobic metabolism i.e. the use of oxygen to meet the energy requirement during exercise [2]. For the first time, Dr. Kenneth H Cooper conducted research on aerobic exercise in 1960s over U.S. Air force personnel. He considered running, jogging, swimming, cycling, and walking as aerobic exercise [3].

Talking about the effects of aerobic exercise, these mostly constitute the improvement of pumping effect of the heart; reduction of blood pressure and resting heart rate of an individual [4-6], strengthening of the respiratory muscles and improving its endurance [7], Improvement of mental health, cognitive capacity and alertness also occur [8]. If aerobic exercises are done consistently on a regular basis it helps in fat loss [9].

Breathing is very important for maintenance of life. It is derived from Sanskrit word pranayama which means development of breath [10]. Regular practice of breathing exercise induces different types of physiological changes in healthy individual [11]. Many researchers also claimed for improvement of pulmonary function through breathing exercise, during their studies [10, 12]. It is also helpful in reducing blood pressure and heart rate [11-13]. Different breathing and patterns of breathing is being practiced on people for stress management, for treatment of anxiety disorder and in order to improve the psychological health [14-15].

There are many comparative studies between yoga and aerobic exercise [16], yoga and swimming [17], aerobic and anaerobic exercise [18], slow breathing and fast breathing exercise [15], breathing exercise and aerobic exercise in asthma [19,20]. But there is lack of comparative study between aerobic and breathing exercises on general health of asymptomatic population. The aim of the present study is to evaluate the effectiveness of breathing exercises against aerobic exercises in improving the general health of asymptomatic population. 


\section{Methodology}

The population of this prospective, pre- test and post-test experimental study consisted of 36 healthy asymptomatic subjects of both sex between the age group of 20-45 years. The subjects who meet the exercise readiness questionnaire were included in the study. The person having diabetes mellitus, uncontrolled hypertension, pregnancy, activity restriction due to disease, unstable cardiac or pulmonary disease, and significant arthritis were excluded from the study. The selected subjects were randomly assigned to breathing and aerobic exercise group. The following tests were performed before and after the exercise programme: The subjects were asked to sit comfortably and relax for 30 minutes then pulse rate was measured by palpating the radial artery and blood pressure was measured by using Mercurial Sphygmomanometer and stethoscope. Vital capacity and MVV was measured by computerised spirometer (Winspiro PRO: Spirometer). Skin fold thickness was measured by skin fold calliper at subscapular region, supra-iliac region and abdomen, after that sum of the skin folds was calculated which reflects absolute or percentage changes in body fat [21]. $\mathrm{VO}_{2} \mathrm{max}(\mathrm{ml} / \mathrm{kg} / \mathrm{min})$ was measured using 'Cooper 12 Minute Walk test', total distance was recorded in meters they had travelled in 12 minutes then it converted in kilometre and put it in the formula: VO2 $\max =(22.351 \mathrm{x}$ kilometres $)-11.288$ $[22,23]$. In order to determine health related quality of life RAND 36 -Item health survey 1.0 scales was used. It includes 36 questions that cover eight dimensions of HRQL. The 8 dimension are physical functioning, bodily pain, role limitations due to physical health problems, and role limitations due to personal or emotional problems, emotional well-being, social functioning, energy/fatigue, and general health perceptions [24, 25].

\section{Procedure}

Subjects who fulfilled the inclusion and exclusion criteria were recruited. The procedure of the study was explained to the subjects in detail. Those who were willing to participate in the study, were asked to sign the inform consent form. The subjects were then randomly assigned into 2 groups-Breathing group (gr-1) and Aerobic group (gr-2). All participants underwent an initial baseline assessment. The resting pulse rate, blood pressure, PFT, skin fold thickness, $\mathrm{VO}_{2} \mathrm{Max}$, HRQOL were tested, by investigator .The exercise was started the day after the measurement was taken. Subjects in group-1 received breathing exercise and group- 2 received aerobic exercise. Both breathing exercise and aerobic exercise were performed in three phases, each phase consists of two weeks, and both groups performed warm up before exercise and cool down after exercise. In the first phase, breathing exercise was performed in supine, sitting and standing position with inspiration to expiration ratio of 1:1 and total duration of exercise was 15 minute. In the second and third phase, breathing exercise was performed in supine, sitting, standing and crook lying position but inspiration to expiration ratio in second phase was 1: 2 and total duration of exercise was 20 minutes, in the third phase there was a breath hold time, so inspiration: breath hold: expiration ratio was 1:2:2 and total duration of exercise was 30 minutes. Aerobic exercise group performed cycling, stair climbing and walking on the ramp, and intensity of exercise was moderate- $60 \%$ of MHR (Age predicted) of the subjects. Duration of exercise was 15 minutes, 20 minutes and 30 minutes in phase 1, phase 2 and phase 3 respectively. Both the groups received exercise 5 days in a week for 6 weeks. It was confirmed that none of the subjects in the study received any other form of exercise. The data were collected after 6 weeks.

\section{Data Analysis}

The data was analysed with SPSS (Statistical Package for Social Sciences) 23 version. Cardiorespiratory parameters and skin fold thickness were analysed using $2 \times 2$ ANOVA, with repeated measurement as a second factor. There was one between factor (Group 1- Breathing group \& Group 2- Aerobic group) and one within factor (time) with 2 levels (pre \& post treatment measures). Post- hoc comparison was done using a 0.05 level of significance. Mann Whitney $U$ test was used to find the significance between the 2 groups for RAND 36-Item Health Survey 1.0 Questionnaire (HRQOL).

\section{Results}

\section{Pulse rate}

For both breathing group and aerobic group, the pulse rate was reduced after the intervention then at base line however, there was no significant difference between the groups. Graph 1 illustrates the reduction from pre to post of both the groups (breathing exercise and aerobic exercise) in pulse rate with no significant difference between the groups. 


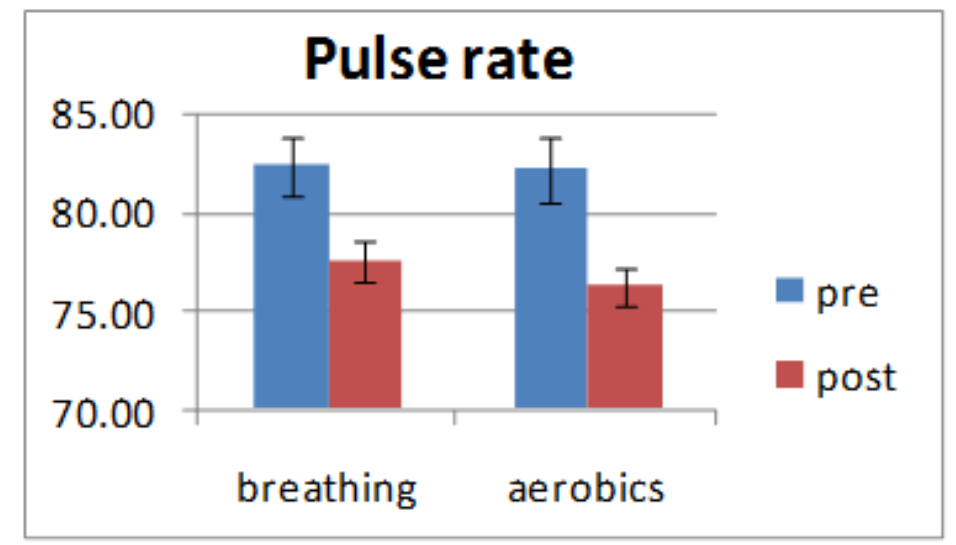

Graph- 1: Pulse Rate

\section{Systolic Blood pressure}

For both breathing group and aerobic group, the systolic blood pressure was reduced after the intervention then at base line; however there was no significant difference between the groups. Graph 2 illustrates the reduction from pre to post of both the groups (breathing exercise and aerobic exercise) in systolic blood pressure with no significant difference between the groups.

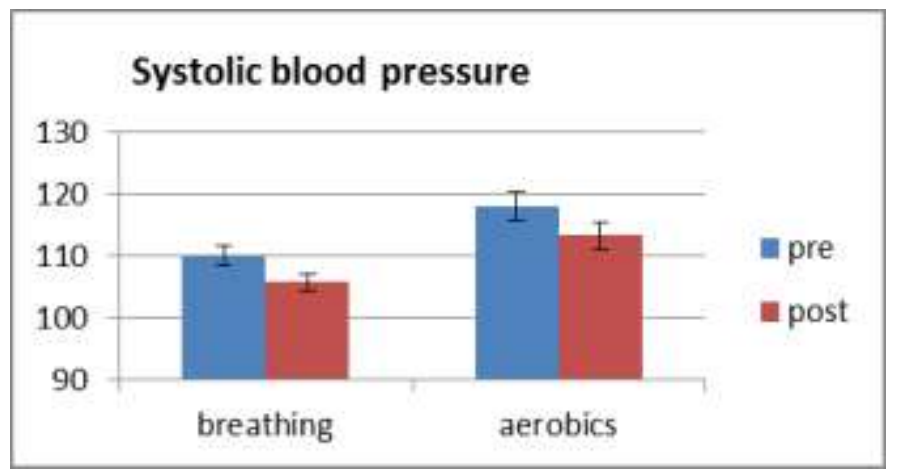

Graph- 2: Systolic Blood pressure

\section{Diastolic Blood pressure}

For both breathing group and aerobic group, the diastolic blood pressure was reduced after the intervention then at base line however, there was no significant difference between the groups. Graph 3 illustrates the reduction from pre to post of both the groups (breathing exercise and aerobic exercise) in diastolic blood pressure with no significant difference between the groups.

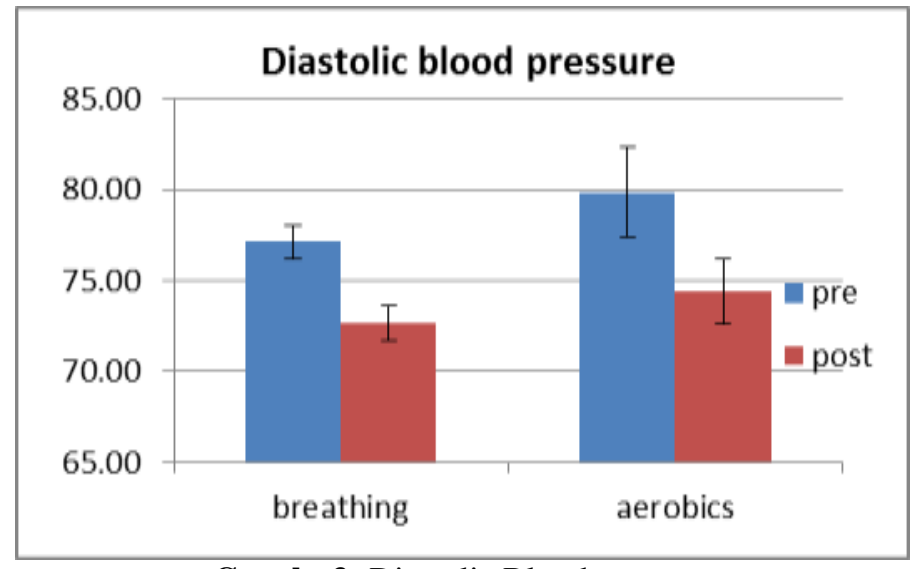

Graph- 3: Diastolic Blood pressure 


\section{Vital Capacity}

For both breathing group and aerobic group, vital capacity was improved after the intervention then at base line however, there was no significant difference between the groups. Graph 4 illustrates the improvement from pre to post of both the groups (breathing exercise and aerobic exercise) in vital capacity with no significant difference between the groups.

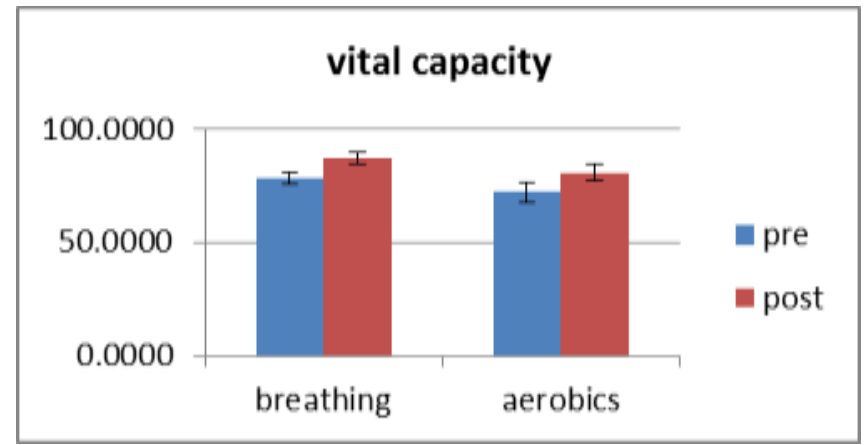

Graph -4: Vital Capacity

\section{MVV}

For both breathing group and aerobic group, MVV was improved after the intervention then at base line however, there was no significant difference between the groups. Graph 5 illustrates the improvement from pre to post of both the groups (breathing exercise and aerobic exercise) in MVV with no significant difference between the groups.

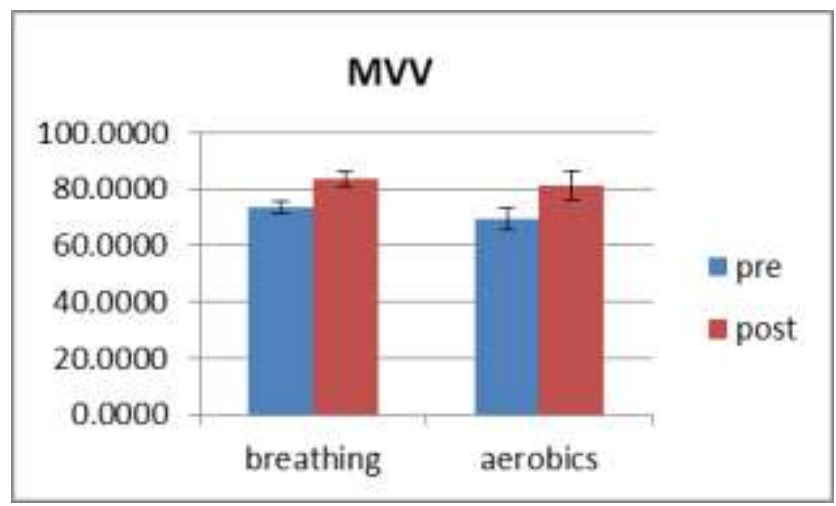

Graph- 5: MVV

\section{$\mathrm{VO}_{2} \mathrm{Max}$}

For both breathing group and aerobic group, $\mathrm{VO}_{2} \mathrm{Max}$ was improved after the intervention then at base line however, the improvement was significantly more in aerobic exercise group as compared to breathing exercise group $(\mathrm{p}<0.05)$. Graph-6 summarizes improvement in $\mathrm{VO}_{2} \mathrm{Max}$ from pre to post in both groups.

\begin{tabular}{ccc}
\multicolumn{3}{c}{$\mathbf{V O}_{\mathbf{2}} \mathbf{m a x}$} \\
20.0000 & & \\
10.0000 & & \\
0.0000 & & pre \\
& breathing $\quad$ aerobics & \\
& Graph- 6: $\mathrm{VO}_{2} \mathrm{Max}$ &
\end{tabular}




\section{Skin fold thickness}

Both groups showed reduction in skin fold thickness from pre to post after the intervention however, the reduction was significantly more in aerobic exercise group as compared to breathing exercise group $(\mathrm{p}<0.05)$. Graph-7 summarizes reduction in skin fold thickness from pre to post in both groups.

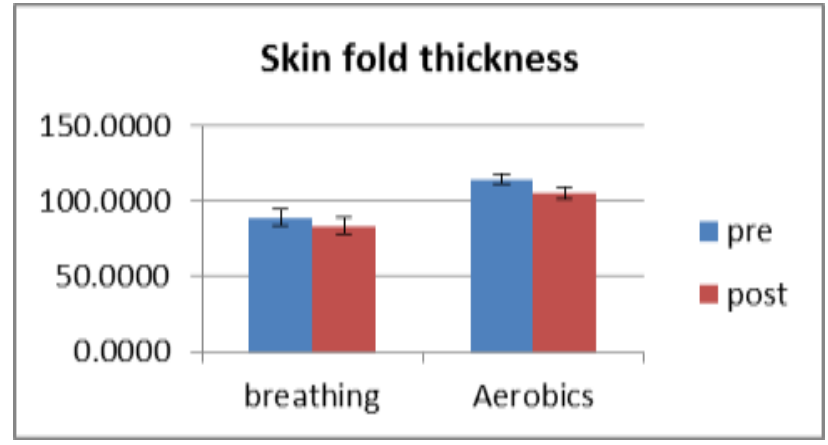

Graph- 7: Skin fold thickness

\section{Health related quality of life}

Health related quality of life improved with both breathing and aerobic exercises from pre to post after intervention, however emotional wellbeing $(\mathrm{p}=.006)$ and social functioning $(\mathrm{p}=.001)$ components, were significantly improved in aerobic group compared to breathing group. Graph- 8 illustrates that both the groups breathing and aerobic similarly improved in quality of life. $(\mathrm{p}=.163)$. However aerobic group improved more (emotional wellbeing and social functioning components, was significantly improved in aerobic group) compared to breathing group.

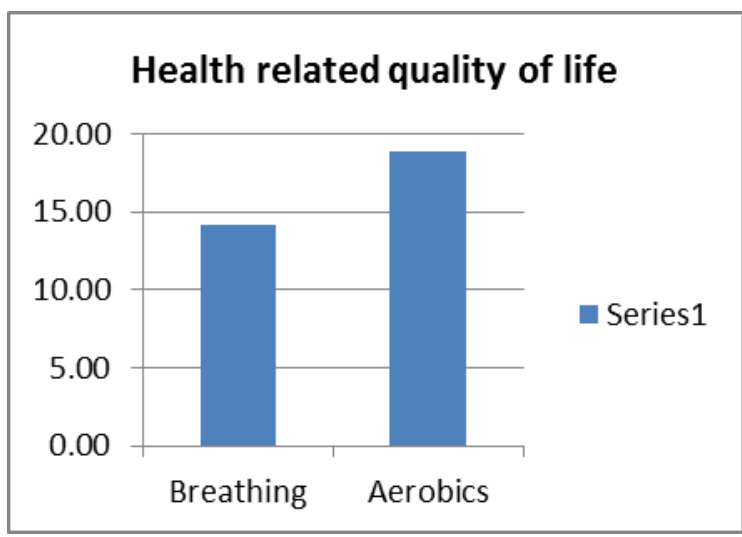

Graph- 8: Health related quality of life

\section{Discussion}

The overall results of the study (comparative study on effect of breathing and aerobic exercise on general health in asymptomatic population) after intervention of 6 weeks, both the groups (breathing and aerobic) improved significantly from pre to post intervention in $\mathrm{VC}, \mathrm{MVV}, \mathrm{VO}_{2}$ max and health related quality of life. It also found that, there was significant reduction in pulse rate, blood pressure and skin fold thickness from pre to post intervention in both the groups. However there was no statistically significant difference between both groups with regard to the above variables except $\mathrm{VO}_{2} \mathrm{Max}$, which was significantly improve more in aerobic group and skin fold thickness which was significantly reduced more in aerobic group.

\section{Cardiorespiratory Parameters}

The findings of the study showed significant reduction in pulse rate (BE group-5.8\%, AE Group-7.2\%), Systolic blood pressure (BE group-3.8\%,AE Group-4.2\%), Diastolic blood pressure (BE group-5.8\%,AE Group-6.8\%) and improvement in vital capacity(BE group-11\%,AE Group-12\%), MVV(BE group-13.5\%,AE Group-17\%) and VO2 Max in both breathing and aerobic group. But there was no significant difference between breathing and aerobic exercise group with regard to the above variables except VO2 Max on which the aerobic group (30\%) improved significantly more than the breathing group (11\%).

In the present study, the reduction in pulse rate and blood pressure in breathing group may be due to tonic and phasic changes in cardiovascular system [11] and parasympathetic activity also increases with regular 
practice of breathing exercise [11,26]. Previously it has been shown in various studies that breathing exercise can results in reduction in blood pressure and heart rate. DP Deepak 2013 found reduction in blood pressure and heart rate with four weeks of anulom vilom pranayama [27]. K U Dhungle et al. 2008 also found reduction in pulse rate, systole and diastolic blood pressure with four weeks of alternate nostril breathing exercise [11]. AV Turnakar et al. 2013 also found reduction in pulse rate after breathing exercise, 20 minute per day for 7 days [26]. In the present study, the reduction in pulse rate in aerobic exercise group may be due to increase parasympathetic activity [6, 28]. This result is consistent with the study done by M K Mishra 2015 showed reduction in heart rate with 6 weeks of aerobic exercise in male students [29]. In the present study, the reduction in blood pressure in aerobic group may be due to decrease peripheral resistance to blood flow and reduced activity of sympathetic nervous system [30]. Seamus PW et al. 2002 in a meta-analysis study found blood pressure reduces in both hypertensive and normotensive patient with aerobic exercise [31]. MA Mughal 2001 found decrease in systolic and diastolic blood pressure $(\mathrm{P}<0.05)$ with 30 minute of walking, 3-5 times per week for 12 weeks [32]. Anderson 1999 also found reduction in blood pressure with structure aerobic exercise [33].

In the present study, the improvement in vital capacity and MVV in both groups may be due to strengthening of respiratory muscles [34, 35]. With regular breathing exercise there was deep inspiration and expiration occur for prolong period, which helps for strengthening of respiratory muscles and lung compliance also increases [34]. Sheetal Panwar et al. 2012 found improvement in MVV (0.001) and vital capacity $(<0.0001)$ with 3 months of pranayam [36]. Baljinder S Bal 2010 also found improvement in vital capacity and MVV with 8 weeks of anulom vilom and bhastrika pranayama [37]. With aerobic exercise forceful inhalation and exhalation occur for prolong period which improve the strength and endurance of respiratory muscles [35]. Anju M Gupt et al 2015 found improvement in MVV, FVC with moderate aerobic exercise training [38]. M Muralikrishna and Shevlam 2014 also found improvement in vital capacity and other cardio respiratory parameters with aerobic training, 5 days per week for 16 weeks [39].

The findings of the study showed improvement in $\mathrm{VO}_{2}$ max in both groups. However there was significant improvement in $\mathrm{VO}_{2}$ max in aerobic group compared to breathing group because, exercise in aerobic group was above the minimal intensity or threshold. It has been shown in previous studies that, exercises above a minimum intensity or threshold is required to improve $\mathrm{VO}_{2} \max [40,41]$. Minimal improvement of $\mathrm{VO}_{2}$ max in this study may be due to decrease peripheral resistance and increase tone of ventilator muscles [42]. Gormley SE 2008 found improvement in vo2 max with moderate, vigorous and maximal intensity aerobic exercise after six weeks of training but they conclude that higher intensities exercise are more effective in improving $\mathrm{VO}_{2}$ Max [43]. P Nandhini 2013 found improvement in $\mathrm{VO}_{2} \max$ with aerobic dance training for five days per week for eight weeks [44].

\section{Skinfold Thickness}

This study demonstrated significant reduction in skin fold thickness in both groups, but there was significantly more reduction in aerobic group (7.9\%) compared to breathing group $(6 \%)$. The reduction in skin fold thickness in breathing group may be due to fooding habits and personal habits. Similar result was shown by U B Kundu 2014 found reduction in skin fold thickness in 8-10 year male after 90 days of pranayama [45].The reduction in skin fold thickness in aerobic exercise group may be due to increase resting metabolism in the body which helps in mobilisation and oxidation of lipid [42]. In this study reduction in skin fold thickness is more in aerobic group compared to breathing group which may be due to increase in estimated daily energy expenditure in aerobic group compare to breathing group, causing caloric expenditure resulting in weight loss. The reduced body fat in aerobic group which intern decreases the skin fold thickness. Similar studies was done by Slentz 2005 found significant decrease in visceral (6.9\%), Subcutaneous (7\%) and abdominal fat with modest exercise programme [46]. Leslie H Willis et al. 2012 found aerobic training was more effective in reducing body fat in sedentary non diabetic obese adults [9]. Robert Ross and Janssen 2004 found reduction in total fat and abdominal fat after 14 weeks of exercise programme [47].

\section{Health Related Quality Of Life (Hrqol)}

This study demonstrated significant improvement in health related quality of life in both the groups breathing exercise group (19.7\%) and aerobic exercise group (21\%). However emotional wellbeing and social functioning components, (components of mental health summary score) was significantly more improved in aerobic group compared to breathing group.

Recently it has been investigated by many researchers that, higher level of cardiorespiratory function was associated with higher level of HRQOL [48, 49]. In the present study, there was improvement in all cardiorespiratory parameters in both breathing and aerobic group except $\mathrm{VO}_{2}$ max, which was improved more in aerobic group. This may be one of the reasons for improvement in HRQOL in both groups (breathing and aerobic). 
In the present study improvement in health related quality of life in breathing group may be due to suppression of sympathetic system [11]. Which leads to reduction in stress and anxiety. This result is consistent with the study done by Sahala N D et al. 2013 showed improvement in pain and quality of life in multiple sclerosis patient with pranayama and yoga for one month [50].

In the present study there was significant improvement in emotional well- being and social functioning components in aerobic group which may be due to deviation from boring and unpleasant daily activity and they also interact with other during group exercise and enjoy social contact [51]. Similar result was shown by Corby K Martin et al. 2009 found significant improvement in all dimension of quality of life with exercise in sedentary postmenopausal women and improvements in quality of life were dose dependent [52]. Margareeta k Eriksson et al. 2010 also found improvement in physical functioning and social functioning and reduced body pain with exercise and dietary counselling in CVD patient [53].

In the present study, aerobic exercise programme is sufficient to address fear avoidance belief (avoidance of behaviour based on pain related fear) and improve physical functioning and quality of life [54]. This study supported by Paul Marshall et al. found improvement in general health and pain reduces with eight weeks of stationary cycling and specific trunk exercise programme in LBA [54]. Aerobic exercise reduced fatigue, improve- endurance, aerobic capacity and physical activity and It also reverses the cycle of deconditioning $[55,56]$. Similar result was shown by Giannini M and Protas EJ et al. found improvement in aerobic capacity (energy and activity level) with aerobic exercise in juvenile rheumatoid arthritis patient [57]. Iversen Maura D et al 2003 also found improvement in physical functioning, energy level (improvement in SF36 score) with cycling programme in older population [58].

\title{
Limitations
}

Small sample size

Carry over effect of the exercise group was not observed.

Skin fold, one of variables - diet chart should maintain throughout study period for uniform results.

\section{Suggestions}

A long term follow up study may be done.

Flexibility, weight should also be check to see its effect.

The study should be done on either male or female to control the effect of sexual variance.

\section{Conclusion}

Breathing exercise and Aerobic exercise improved cardio respiratory parameter and quality of life similarly. However, aerobic exercises has better effect in reduction of skin fold thickness and improvement in $\mathrm{VO}_{2} \mathrm{Max}$ with 6 weeks intervention in healthy subjects.

\author{
Abbreviations: \\ PR-Pulse rate \\ SBP-Systolic blood pressure \\ DBP-Diastolic blood pressure \\ VC-Vital capacity \\ MVV-Maximal voluntary ventilation \\ AE -Aerobic exercise \\ BE -Breathing exercise \\ HRQOL- Health related quality of life
}

\section{References}

[1]. Sephard RJ (1989) Adolphe Abrahams memorial lecture. Exercise and life style change. British journal of sports and medicine. 23(1): $11-22$

[2]. Plowman SA, Smith DL (2007) Exercise physiology for Health, Fitness, and performance. $2^{\text {nd }}$ ed. Lippincott William and Wilkins.

[3]. Cooper KH (1983) Aerobics. Bantam books.

[4]. Scheuer J, Tipton CM (1977) Cardiovascular adaptations to training. Annual reviews of physiology. 39: 221 - 251.

[5]. Seals DR, Silverman HG, Reiling MJ, Davy KP (1997) Effect of regular exercise on elevated blood pressure in postmenopausal women. Am J Cardiol. Elsevier. 80(1): 49 - 55.

[6]. Almedia MB, Araujio CGS (2003) Effects of aerobic training on heart rate. Rev Bras Med Esporete. 9(2): 113 - 120.

[7]. Azad A, Gharakhanlou R, Niknam A, Ghanbari A (2011) Effects of aerobic exercise on lung function in overweight and obese students. Tanaffos. 10(3): $24-31$.

[8]. Bluementhal JA, Williams RS et al. (1982) Psychological changes accompany aerobic exercise. Psychosom Med. 44(6): 529 - 36.

[9]. Willis HL, Slentz CA, Bateman LA et al. (2012) Effects of aerobic and /or resistance training on body mass and fat mass in overweight or obese adults. Journal of applied Physiology. 113(12): 1831 - 1837.

[10]. Blessy V, Sayyad R, Yadav PK, Kar SK (2014) Effect of breathing exercises on pulmonary function tests in healthy adults. Journal of Clinical and Biomedical Sciences. 4(1): $226-29$. 
[11]. Dhungel KU, Malhotra V, Sarkar D, Prajapati R (2008) Effect of alternate nostril breathing exercise on cardiorespiratory functions. Nepal Med Coll J. 10(1): 25 - 27.

[12]. Joshi LN, Joshi VD, Gokhle LV (1992) Effect of short term pranayam practice on breathing rate and ventilatory functions of lung. Indian J of physiol and pharmacol. 36(2): $105-108$.

[13]. Prasad RK, Dhapola MS (2015) Effect of pranayama practice on selected physiological variables of university kabaddi players. Golden research thoughts. 4(7): $1-8$.

[14]. Sakakibara M, Hayno J (1996) Effect of slowed respiration on cardiac parasympathetic response to strss. Psychosom Med. 58: 32 7.

[15]. Sharma VK, Trakroo M, Subramaniam V, Bhabani AB, Sahay A (2013) Effect of fast and slow pranayama on perceived stress and cardiovascular parameters in young health care students. International journal of yoga. 6(2): 104-110.

[16]. Mirzaee Z, Jamshidi AA, Babaali M, Nezhad SB (2015) The effect of an eight week yoga and aerobic exercise on selected biomechanical parameters in 30-40- year women. Indian journal of fundamental and applied life sciences. 5(S3): $773-775$.

[17]. Gupta SS, Sawane MV (2012) A comparative study of the effects of yoga and swimming on pulmonary functions in sedentary subjects. International journal of yoga. $128-133$.

[18]. Saif AA, Alsenany S (2015) Aerobic and anaerobic exercise trainning in obese adults. J of phys ther sci. 27 (6): 1697 - 1700.

[19]. Sakshi, Multani (2010) Comparision of breathing exercises and aerobic exercise in asthmatic children. Journal of exercise science and physiotherapy. 6(2): $112-119$.

[20]. Evaristo et al. (2014) Comparision between breathing and aerobic exercise on clinical control in patients with moderate to severe asthma. BMC Pulmonary medicine. 14: 160.

[21]. Johnson BL, Nelson JK (1982) Practical measurement for evaluation in physical education. $3^{\text {rd }}$ ed. Surjeet Publication. Delhi. India. $165-67$.

[22]. Cooper KH. (1968) A means of assessing maximal oxygen uptake. JAMA. 203: $201-4$.

[23]. Bandyopadhya A. (2015) Validity of cooper`s 12-min run test for estimation of maximum oxygen uptake in male university students. Biology of sports. 32(1): $59-63$.

[24]. Gaskin CJ, Morris T (2008) Physical activity, Health related quality of life, and psychosocial functioning of adults with cerebral palsy. Journal of physical activity and health. 5: $146-157$.

[25]. Hays RD, Morales LS (2001) The RAND -36 measure of health related quality of life. The Finnish Medical society Duodecim. Ann Med. 33(5): $350-357$.

[26]. Turankar AV, Jain S, Patel SB, Joshi AD, Vallish BN, Mane PR (2013) Effects of slow breathing exercise on cardiovascular functions, pulmonary functions and galvanic skin resistance in healthy human volunteers-a pilot study. Indian J Med Res. 137(5): $916-921$.

[27]. Dandekar PD (2013) Impact of short term training of anulomvilom pranayama on blood pressure and pulse rate in healthy volunteers. Int J Res Ayurveda Pharm. 4(2): 253 - 256.

[28]. Mikahil C, Forti VAM, Catai AM et al. (1998) Cardiorespiratory adaptations induced by aerobic training in middle aged men: the importance of a decrease in sympathetic stimulation for the contribution of dynamic exercise tachycardia. Brazilian journal of medical and biological research. 31(5): $705-712$.

[29]. Mishra MK, Rathore VS (2015) Effect of six weeks training of aerobic exercise on selected physiological variables. International journal of physical education, Sports and health. 2(2): $116-118$.

[30]. Cornelissen VA, Fagard RH (2005) Effects of endurance training on blood pressure, blood pressure regulating mechanisms, and cardiovascular risk factors. Hypertension (American heart association). 46: $667-675$.

[31]. Whelton SP, Chin A, Xin X, He J (2002) Effect of aerobic exercise on blood pressure: a meta- analysis of randomized, controlled trials. Ann intern Med. 136(7): 493 - 503.

[32]. Mughal MA, Alvi IA, Akhund IA, Ansari AK (2001) The effects of aerobic exercise training on resting blood pressure in hypertensive patients. JPMA. 51: 222.

[33]. Anderson RE et al. (1999) Effects of life style activity Vs structured aerobic exercise in obese women. JAMA. 281(4): 335 - 340

[34]. Mamtha SD, Gorkal AR (2012) Effect of savitri pranayama practice on peak expiratory flow rate, maximum voluntary ventilation and breath holding time. IJRRMS. 2(1): 7 - 11

[35]. Mahajan S, Arora AK, Gupta P (2013) Effect of aerobics training on pulmonary functions in young male adults of Punjab. Pak J Physiology. 9(2): $23-25$.

[36]. Sheetal P, Ashutosh C, Jayant M (2012) Effect of pranayama on pulmonary function tests of young healthy students. Int Journal Bio Sci. 3(4): $12-16$.

[37]. Bal BS (2010) Effect of anulom vilom and bhastrika pranayama on Vital capacity and maximal ventilatory volume. Journal of physical education and sport Management. 1(1): $11-15$.

[38]. Gupt AM, Kumar M, Sharma RK, Misra R, Gup A (2015) Effect of moderate exercise training on pulmonary functions and its correlation with the antioxidant status. National journal of medical research. 5(2): 136 - 139.

[39]. Muralikrishna M, Shevlam PV (2014) Effect of different intensities of aerobic training on vital capacity of middle aged obese men. International journal of current research and academic review. 2(8): 85 - 90.

[40]. Franklin BA, Swain DP (2003) New insights on the threshold intensity for improving cardiorespiratory fitness. Preventive cardiology. 6(30: $118-121$

[41]. Garber CW et al. (2011) Quantity and quality of exercise for developing and maintaining cardiorespiratory, musculoskeletal, and neuromotor fitness in apparently healthy adults: Guidance for prescribing exercise. Medicine and science in sports and exercise. American college of sports medicine. 43(7): 1334 - 1359.

[42]. Jaywant (2013) Effect of aerobic dance on the body fat distribution and cardiovascular endurance in middle aged women. Journal of exercise science and physiotherapy. 9(1): $6-10$.

[43]. Gromley SE, Swain DP (2008) Effect of intensity of aerobic training on $\mathrm{VO}_{2}$ Max .Med Sci Sports Exerc. 40(7): 1336 - 43 .

[44]. Nandhini P (2013) Effect of aerobic training on maximal oxygen uptake of college women. International journal of innovative research and development. 2(6): $823-827$.

[45]. Kundu UB (2014) Impact of asanas and pranayamas on body fat percentage of school going children. Journal of international academic research for multidisciplinary. 2(8): $16-20$.

[46]. Slentz CA, Aiken LB, Houmard JA et al. (2005) Inactivity, exercise, and visceral fat. Strride: A randomized, controlled study of exercise intensity and amount. Journal of applied physiology. 99: 1613 - 1618.

[47]. Ross R, Janssen I et al. (2004) Exercise induced reduction in obesity and insulin resistance in women: a randomized controlled trial. Obesity A research journal. 12(5): 789 - 798. 
[48]. Solan RA, Sawada SS et al. (2009) Association between cardiorespiratory fitness and Health related quality of life. Health and quality of life outcomes. Biomed central. 7: 47.

[49]. Clenin MN, Payne JPW, Rienzi EG et al. (2015) Association between cardiorespiratory fitness and health related quality of life among patients at risk for cardiovascular disease in Uruguay. Plos one. 10(4): 1 - 14.

[50]. Doulatabad SN, Nooreyan K et al. (2013) The effects of pranayama, hatha and raja yoga on physical pain and the quality of life of women with multiple sclerosis. African Journal of traditional, complementary and alternative medicine. 10(1): 49-52.

[51]. Smoll FL, Schutz RW (1980) Children`s attitudes toward physical activity: A longitudinal analysis. Journal of sport psychology. 2 : $137-147$.

[52]. Martin CK, Church TS, Thompson AM, Earnest CP, Blair SN (2009) Exercise dose and quality of life- A Randomized Controlled Trial. Arch intern med. 169(3): $269-278$.

[53]. Eriksson MK, Hagberg L et al. (2010) Quality of life and cost effectiveness of a 3 year trial of lifestyle intervention in primary health care. Arch of intern Med. 170(16): 1470 - 1479.

[54]. Marshall PWM, Kennedy S, Brooks C, Lonsdale C (2013) Pilates exercise or stationary cycling for chronic nonspecific low back pain: Does it matter? A randomized controlled trial with 6-month follow up. Spine. 38(15): E952 - E959.

[55]. Minor MA, Hewett JE, Webel RR, Anderson SK A, Kay DR (1989) Efficacy of physical conditioning exercise in patients with rheumatoid arthritis and osteoarthritis. Arthritis and Rheumatism. 32(11): 1396 - 1405.

[56]. Smeets RJEM, Wittink H, Hidding A, Knottnerus JA (2006) Do patients with chronic low back pain have a lower level of aerobic fitness than healthy controls? Are -pain, disability, fear of injury, working status or level of leisure time activity associated with the difference in aerobic fitness level? Spine. 31: $90-97$.

[57]. Giannini MJ, Protas EJ (1991) Aerobic capacity in juvenile rheumatoid arthritis patients and healthy children. Arthritis care and research. 4(3): $131-135$.

[58]. Iversen MD, Fossel AH, Katz JN (2003) Enhancing function in older adults with chronic low back pain: A pilot study of endurance training. Arch Physical Medicine and Rehabilitation. 84(9): $1324-31$. 